\title{
Interference in English Language Learning Among Indonesia Students
}

\author{
Fauzia
}

\section{ARTICLE INFO}

Article History:

Received 03.03.2019

Received in revised form

12.12.2019

Accepted

Available online 01.01.2020

\begin{abstract}
English has been considered to be first foreign and second language in Indonesia It functions to help the development of the state and nation, to build relation with other nations, and to run foreign policy including as a language used for wider communication in international forum. There are a lot of problems found in the English learning language learning. One of kind is interference. Interference means the influence that the learner's L1 exerts over the acquisition of an L2. There are several causes of interference in language learning, which are: 1) bilingualism, 2) the similarity between the shape of L1 and L2, and 3) the ease for second language learners
\end{abstract}

(C) IJERE. All rights reserved

Keywords:

Interference, language, learning.

\section{INTRODUCTION}

The topic of 'first language interference' has had an unusual history in second language acquisition research and practice. For many years, it had been presumed that the only major source of syntactic errors in adult second language performance was the performer's first language (Krashen: 2002). However, subsequent empirical studies of errors made by second language students led to the discovery that many errors are not traceable to the structure of the first language, but they are common to second language performers of different linguistics backgrounds (Krashen: 2002). These findings have led several scholars to question the value of contrastive analysis and to argue instead for error analysis.

Interference based on (Ellis: 1986) defines as 'transfer', which he says is 'the influence that the learner's L1 exerts over the acquisition of an L2'. In SLA, interference works as follows, where the first and second language share a meaning, but express it in different ways, an error is likely to arise in the L2 because the learner will transfer the realization device from his first language into the second. According to (Shastri et al., 2009) the term interference is derived from a learning theory approach that explains about the process of habit formation constitues in language learning. Interference included those errors that occur in the learning of a second language.

Ertmer (1999) in Soulaymani (2018) has highlighted two major categories of obstacles in the learning process. Firstly, the extrinsic obstacles of first-rate, on issues related to access, time, support, resources and training, and, on the other hand, intrinsic barriers called second order indicators. As examples, the attitudes, beliefs, practices and the resistance of teachers.

Egbert and Hanson-Smith (1999) in Azmina (2018) as a "learners (1) have opportunities to interact and decipher meaning, (2) interact in the target language with an authentic audience, (3) are involved in authentic tasks, (4) are exposed to, and encouraged to produce, varied and creative language, (5) are given enough time and feedback, (6) are helped to attend mindfully to the learning process, (7) work in an atmosphere with ideal stress levels, and (8) are allowed autonomy and supportive behavior" (p. 1-2).

Strategies for Second-Language Production

The term " second language" or L2 in SLA literature refers to "any language learned after learning the L1, regardless of whether it is the second, third, fourth, or fifth language (Kadarisman, 2015).

Referring to L1 as the starting point and L2 as the end point, there is a term called by interlanguage. As the name indicates, it suggests the "learner language" in the process of becoming, moving -at it were - from L1 as a point of departure toward L2 as a point of destination. In this respect, systematic "errors" occuring in

University of Ahmad Dahlan, fauzia@pbi.uad.ac.id. orcid.org/0000-0003-1108-0053 
the interlanguage at one point of time along its course of development may be seen as reflection of the current state of interlanguage competence (Kadarisman, 2015)

Moreover Krashen (2002) states that because errors are easy to observe and are good indicators of a person's level of second-language knowledge, there have been many good studies done on errors. There is some confusion, though, when it comes to interpreting just what the cause of errors might be. In our opinion, only a minority of errors can be attributed to interference, where the first language intrudes on the second. Rather, most errors are systematic, being the result of the application of what we shall call the 'FirstLanguage Strategy' and 'The Second-Language Strategy'. These strategies are applied when relevant secondlanguage knowledge is not yet available or is incomplete. Consider the following errors made by Japanese university students while writing answers to an examination question.

Example:

Now Tom happy is.

For the student who has had years of English and knows English word order well, it is likely that this is a case of interference. In the process of constructing the sentence, perhaps because of haste (native speakers too make errors when in a hurry), the Japanese order of constituents intruded on the process so as to cause the error (Krashen, 2002).

Furthermore, Krashen (2002) states some findings on first language influence on second language acquisition and performance.

First language influence appears to be strongest in complex word order and in word-for -word translations of phrases

Evidence for this generalization comes from several sources, for example, studied written errors of Czech concluded that interference from the mother tongue was plainly obvious in errors of word order and sentence construction, a common example being the placement of the direct object after an adverbial, as in:

I met there some Germans.

It is also present in the compositions were many word-for word translations of Czech expressions into English, such as 'another my friend' instead of 'another friend of mine' (Krashen: 2002)

The studies of American college students learning Spanish and German in the US, a foreign language situation, reported that the 'high incidence of interlingual (L1 interference) errors' in German was due to word order errors.

First language-based errors in Spanish were less numerous and 'pertained primarily to adjective position.' The greater word order differences between English and German as compared to English and Spanish accounts for the differences in frequencies in interference word order errors. Spanish students were more often correct in using English surface structures in utterance initiation due to the greater surface similarity between English and Spanish.

English Spanish interference errors occurred mainly 'on grammatical categories absent in either the NL or 'TL' and not in word order. It also found that second level Spanish students showed an increase in interference type errors that calls 'whole expression terms', or word-for-word translations of an L1 expression.

The first is with the sentences. Sentences are also produced following the rules of the language. In one language, the word order for a noun phrase is that the adjective comes before the noun as in the English phrases 'old man', 'rich person', and 'expensive car'. If the noun phrase refers to something already known, the article the must be added and that it must be added before the words old, rich, and expensive, thus forming the new phrases 'the old man', 'the rich person', 'the expensive car', etc. In another language the rule may be different; the adjective must follow the noun, and the article equivalent to the comes last. Thus in language such as Indonesian, the noun phrase is a mirror reflection of English noun phrase: orang tua itu, orang kaya itu, and kereta mahal itu where the order is noun-adjective-article. 
First language influence is weaker in bound morphology

It notes that errors in bound morphology (e.g. Omission of plurals on nouns, lack of subject-verb agreement, adjective-noun agreement is not due to first language in Czech students of EFL: Czech nouns do not distinguish singular and plural and in Czech 'the finite verb agrees with its subject in person and number.' These errors are, rather, 'interference between the other terms of the English subsystem in question'. Moreover, these errors 'occur even in cases where the English form is quite analogous to the corresponding Czech form of 166 morphological errors, only nineteen were judged as due to Czech interference.'

On the sentence level, languages have word orders. Since subjects, verbs, and objects are normally the major elements in sentences, the word order in language can be of various types. There are languages with the word order of subject, verb, and object-SVO. Languages such as English and Indonesian have this basic word order.

First language influence seems to be strongest in 'acquisition poor' environments

Krashen (2002) have demonstrated that first language influence is rare in child second language acquisition. On the other hand, studies report that a high amount of first language influence, such as those cited above, are mostly foreign and not second language studies, situations in which natural appropriate intake is scarce and where translation exercises are frequent. In this regard, it is interesting to note that it can find signs of first language influence in immersion bilingual programs where input is often primarily from the teacher and not from peers. First language influenced errors here are also in the domain of word order (Krashen: 2002)

From the above discussion, it can be attempt to integrate these findings and fit them into the Monitor Model for performance. First, it is considering to proposal for a mechanism for first language influence. First language influence is not proactive inhibition, but is simply the result of the performer being 'called on to perform before he has leaned the new behaviour'. The result is 'padding', using old knowledge, supplying what is known to make up for what is not known. Newmark suggests that the 'cure for interference is simply the cure for ignorance: learning" (in terms of Monitor Theory, this would read "acquisition"). What can be concluded from the above is that the L1 may "substitute" for the acquired L2 as an utterance initiator when the performer has to produce in the target language but has not acquired enough of the L2 to do this.

First language influence may therefore be an indication of low acquisition. If so, it can be eliminated or at least reduced by natural intake and language use. This is what apparently occurred in Taylor's ESL subjects, who showed less first language influence with more proficiency (Krashen: 2002).

Phonetics and Phonology

(Dardjowidjojo, 2009) said in phonology there is a discussion about the arrangement of sounds to form a syllable or a word. Comparing English and Indonesian, it will find that Indonesian also has the sound [1] and [p]. But if it looks at the phonotactic rules of Indonesian, it will see that [1] and [p] never occur together in one syllable or a word. Since [lp] is not found in Indonesian, the English word 'help' is often pronounced as [heləp]. The same is true with the word 'film' which is pronounced as [filəm] or even [piləm]. As for the sound [n], Indonesian allows it to occur at the beginning of a syllable or a word while English does not. Witness the Indonesian words such as ngopi. Native English speakers would find it difficult to pronounce the Indonesian words above. They would come up with something like [nэpi]-[ə๖əpi] (Dardjowidjojo, 2009).

In English a syllable or a word may begin with two or three consonants. If a syllable or word begins with two consonants, the first consonant can be any sound except [h], [v], [z], etc. So, there are no English words such as *[hrima], etc. If it has three consonants, the first can only be [s]. Thus we have 'spray', 'split', and 'screw.' This is the underlying rule that explains why native English speakers would reject words such as the three above intuitively. The nonexistent word blick sounds very much English. Native speakers would say that it sounds and looks English; he just does not know what it means (Dardjowidjojo, 2009).

Indonesian syllables, on the other hand, follow a rather simpler rule, for instance, [pr] as in praja, [br] as in brambang, [tr] as in tri, [dr] as in drama, and [gr] as in graha. It has also rather complex forms such as stamina, struktur, and even psikologi in which [ps] is an unusual form in any language. If it looks as these 
words, virtually all of them are the product of borrowing from other languages such as Sanskrit, Dutch, and English (Dardjowidjojo, 2009).

Sounds and Letters

(Dardjowidjojo, 2009) said that sounds are not letters. A sound, however, may be represented graphically by letters, but a sound is not synonymous with a letter. The words 'he', 'hit', 'sing', and 'breath' consist of two, three, four, and six letters (often referred to as graphemes), namely, $\langle\mathrm{h}-\mathrm{e}\rangle,\langle\mathrm{h}-\mathrm{i}-\mathrm{t}\rangle,\rangle \mathrm{s}-\mathrm{i}-\mathrm{ng}\rangle$, and $<\mathrm{b}-\mathrm{r}$-e-a-t-h $>$ respectively. However, when we pronounce these words, each consists of only two, three, and four sounds. See the representation below:

$$
\begin{aligned}
& \text { He -- }[\mathrm{h}]+[\mathrm{i}] \\
& \text { Hit -- }[\mathrm{h}]+[\mathrm{r}]+[\mathrm{t}] \\
& \text { Sing -- }[\mathrm{s}]+[\mathrm{r}]+[\mathrm{y}] \\
& \text { Breath }-[\mathrm{b}]+[\mathrm{r}]+[\theta]
\end{aligned}
$$

It can say, therefore, that there is no one-to-one correlation between sounds and letters. One sound may be represented by one letter or a combination of letters. For example, the sound [i] can be represented in English by the letter or letters <e> as in be, <ee> as in 'week', <ea> as in 'weak', <eo > as in people.

$$
\begin{aligned}
& \text { <e>--be } \\
& \text { <<ee>>--week } \\
& \text { <ea>--weak } \\
& \text { <eo>--people }
\end{aligned}
$$

On the other hand, one letter or combination of letters may represent more than one sound. For example, the letter $<\mathrm{e}>$ may represent [i] as in be as well as [e] as in 'bet'; the letters $<\mathrm{gh}>$ may be pronounced as $[\mathrm{g}]$ as in 'ghost' as well as [f] as in 'cough'.

The noise that a human produces when communicating with another human is a sound. This sound is different from non-human sounds or from the sounds that an animal produces. The human sound or combination of sounds brings about meanings. The combination of the sounds [b], and [ $\mathrm{v}]$, and $[\mathrm{k}]$, for instance, brings about the meaning of an object that we read or write- a book. This word is in contrast with the word 'bake' pronounced as [bek].

It is clear, therefore, that it should not confuse sounds with letters-or, more technically later, phonemes with graphemes. English is notorously known as the worst spelled language. Anyone learning English must pay a special attention to this phenomenon (Dardjowidjojo, 2009).

First-language and Second-Language Relations Affect Learnability

(Steinberg: 2001) stated that transfer effects of the first language on the learning to the second language: What one's first language is will affect one's learning of the second language. Thus, not every second language will be learned at the same rate. The nature of the similarity relationship between the first and second languages will determine the rate of learning. For example, after having learned English as a first language, learning French would not be as difficult as would learning Japanese. There are differences between English and French syntax, but these differences are small in comparison to the monumental differences between the syntax of English and Japanese.

To the extent that two languages have similarities, such as the position of the article (as in England and French), gender (designation of nouns as masculine or feminine, as in French and Italian), obligatory marking of nouns for plurality, and similar syntactic structures as in English and French), there will be a greater facilitation. There is that much less for the second-language learner to learn.

The aim of this research is: 1) to describe about interference in language learning and 2) factors that cause interference

\section{METHOD}


The method used in this research is descriptive method. Descriptive method has been research conducted aims to describe the data naturally. This is in line with the opinion of Djajasudarma (1993) which says that the descriptive method aims to make a factual and accurate description of the data, the nature of the data, as well as the relationship between the phenomenons under study. A technique used in the data collection is the technique refers to the technical data tools stationery. The first step, data concerning the interference is recorded on a data card, and then the data are grouped according to the interference seen in the data. Furthermore, each group of data are identified and assessed for conclusions that are relevant to the purpose of research. Assessment method used in this research is the method of distributional and match. Distributional method used to sort data based on specific criteria in terms of structure.

The data which has been divided grouped into types of interference. Match method is used to assess the English sentence is not a slick through scanning / counterpart in Indonesian. Thus, in writing English sentences can be determined. Source of research data is the data written in the form of English worksheets pronunciation and writing class. This study was conducted in synchronous through assessments in Englishlanguage worksheets are taken randomly in the academic semester 2015/2016.

\section{FINDINGS}

Based on the analysis of several worksheets of students in the class and also the pronunciation of the students in the class pronunciation, then obtained the following results, interferences that occur in Indonesian to English can be found on some of the following examples. The higher the similarity, the faster the learning:

1. The pronunciation of some words in common with student's writings, especially those associated with silent letters. Indonesian tends to pronounce words according to what is written in the form of writing. It is very rare and almost never found in the Indonesian vocabulary that is not pronounced in accordance with the writing. This is because the number of vowel shapes that exist in Indonesian is fewer than the number of vowels that exist in English.

For example:

a. /hamburger/ is pronunced with /humberger/*

b. /tell/ is written with /teel/*

c. /conversation/is written with /confersation/*

In some words, letters are not pronounced or so-called silent letter (Mc.Carthy, 1960) in his book stating that there are some words that are not pronounced, for example, know (sound ' $\mathrm{k}$ ' is not pronounced), salmon (sound 'l' not pronounced), etc. Because the Indonesian did not recognize this, then there are still some students who say 'know' as / know / and 'salmon' as / salmon /, exactly as written. The correct pronunciation to 'know' was /now/ and 'salmon' /samən/. In this case when the form is not found in the L1, so that students tend to produce and pronounce words in the target language / L2 still use the rule found in the first language / L1.

2. The disappearance to be as a subject and auxiliary verb or even double verbs in a sentence, because in the Indonesian language is no exception to this, all the same. Verb in the form which follows the subject to be dependent on the subject being used. In the Indonesian verb in the form to be used following the subject is always the same, but not so with the English language, which to be used must adjust to the subject. Interference that occurs causes students often forget to put in the verb form to be after the subject, for example:

a. She not alone, but with her friend too $\rightarrow$ auxiliary verb 'did' is dissapear.

b. The mother is works $\rightarrow$ double verbs, 'is' and 'works'

3. Subject and verb agreement, especially on the subject of singular and plural, in the Indonesian language does not know this. English and Indonesian are originating from different realms, even though the same structure as a sentence, namely $\mathrm{S}+\mathrm{V}+\mathrm{O}$. However, in English the subject is changed to adjust to gender, for example, the pronoun 'he' (for male), pronoun 'she' (for female), whereas in the plural in English use the 'they', 'we'. Exceptions in the singular, but serves as a plural, i.e. 'you'. Verb in Indonesian basically 
follow the subject, but it does not change. Whereas in English $S+V$, will usually follow the verb form of the existing subjects. Suppose the singular 'he' 'she' and 'it' will always be followed by the verb to be in the form of 'is'. In the plural form such as 'they' and 'we', usually followed by 'are'.

Subject and Verb Agreement also follow the pattern of tenses used, given in English using the form that adapts to the system when the time. Verb is used will change according to the subject and tenses used. Interference in the Indonesian into English is seen when some students are not quite 'aware' using the verb in the form to be used in a sentence. For example:

a. She have permission from her father $\rightarrow$ She has permission from her father

b. Her father give opinion $\rightarrow$ her father gives opinion

It is also found that intereference comes in some plural forms and pronoun in vocabulary, such as:

a. She was going to some place $\rightarrow$ She was going to some places.

b. Two friend $\rightarrow$ two friends.

c. Her father asked her much question $\rightarrow$ Her father asked her many questions.

d. The father wanted to look at the guy $\rightarrow$ Her father wanted to look at the guy.

4. The order of DM and MD

DM recognize Indonesian rule, while the MD is known in English. In this case, students are often confused because of the influence of interference in Indonesian which is then applied in English.

5. The use of different tenses or contradictory statements due course, because the Indonesian did not know this. In the Indonesian description of the time spent will follow the verb used in the sentence. It is often happen when the students made stories. Telling a story in English should be use past tense which is they have to change the tense especially for the verb form, for example:

a. He has waiting for her $\rightarrow$ he had waiting for her.

b. Her father think that... $\rightarrow$ her father thought that...

c. She goes out with her friend $\rightarrow$ she went out with her friend.

$\mathrm{d}$. The movie starts at $07.30 \rightarrow$ The movie started at 07.30.

e. She tell with her father that she wants to watch movie $\rightarrow$ She told to her father that she wanted to watched movie.

f. My friend goes with her boyfriend too $\rightarrow$ My friend went with her boyfriend too.

g. She feel afraid of her father $\rightarrow$ she felt afraid of her father.

6. Use the notes on affixation.

Antonyms in Indonesian did not use affixation (affix) as in English. The process of change by adding the word affixation of the word, for example in the form of a prefix or suffix. In the form of prefix, for example:

a. patient $\rightarrow$ not patient ${ }^{*} \rightarrow$ impatient.

b. lucky $\rightarrow$ unluckyly* $\rightarrow$ unfortunately.

\section{RESULT, DISCUSSION, AND SUGGESTIONS}

Based on the above results it can be concluded that there is first language interference against a second language, in this case the Indonesian toward mastery of a second language is English. Interference found on several things, namely in terms of pronunciation, grammar, subject and verb agreement, sentence order, pronoun, and affixation. Based on these conclusions, the authors suggest that in learning English, students should be given adequate knowledge related to the concept and correct rules in both the first and second languages. In addition, students should be given a sizeable portion of the exercise. The influence of the first language on the second language is inevitable as part of the learning process. Interference is expected to 
bring more positive influence than negative influence. The depth of students' understanding of the differences between the two languages, makes interference in learning English as a foreign language in Indonesia more minimized.

The forms of interference first language, second language Indonesian to English caused by several factors. These factors include the lack of unanimity in the first language to a second language. Inequality in terms of form and rules between first language and second language among others, seen in terms of pronunciation and writing. The more the difference is found, it will be more and more forms of interference are found. Conversely, when there are many similarities then forms a very small possibility of interference occurs.

In addition to the factors bilingualism where one is able to master more than one language, the ease first language materials that can be applied in learning a second language is also a factor contributing to the interference first language to a second language. This research is limited to the discussion related to interference in learning English as a foreign language in Indonesia. Limitations of interference discussed are in the Indonesian language against learning English.

\section{REFERENCES}

Azmina,B., Fauziati,E. \& Drajati,N.A. (2019). Instructional design of call course in Indonesian higher education for future English teachers: A case study. International Journal of Educational Research Review, 4 (2), 223-229. https:// www.ijere.com/fronted//articles/pdf/v4i2/14pdf.pdf.

Djajasudarma, T.F. (1993). Metode linguistik. Bandung: Eresco.

Dardjowidjojo, S.(2009). English phonetics and phonology for Indonesians Jakarta: Penerbit OBOR.

Ellis, R. (1986). Understanding second language acquisition. Oxford: Oxford University Press.

Kadarisman, A. E. (2015). From description to explanation: Essays in linguistics and applied linguistics. Indonesia: MLI.

Krashen, S. D. (2002). Second language acquisition and second language learning. University of Southern California,Unpublished Thesis.

McCarthy, P.A.D. (1960). English pronunciation. A practical handbook for the foreign learner. England: Cambridge.

Sinha,A., Banerjee,N. Sinha,A. \& Shastri, R. K. (2009). Interference of first language in the acquisition of second language. Journal of Psychology and Counseling, 1 (7), 117-122.

Soulaymani,S. \& Alem,N. (2019). Perceptions of Moroccan English teachers towards using facebook as a pedagogical and instructional tool. International Journal of Educational Research Review ,4(1),33-43. https://www.ijere.com/frontend//articles/pdf/v4i1/4-5-1-2018pdf.pdf.

Steinberg, D. D. (2001). Psycholinguistics: Language, mind and world. Second Edition. Longman Pearson Education. 